\title{
O SENSÍVEL EM MERLEAU-PONTY E A EXCITAÇÃO DAS PAIXÕES EM VINÍCIUS DE MORAES
}

\author{
M. S. VIEIRA \\ Universidade Federal do Rio Grande do Norte. Pós-Graduação em Artes Cênicas \\ marciliov26@hotmail.com
}

Artigo submetido em novembro/2015 e aceito em dezembro/2015

DOI: 10.15628/dialektike.2015.3576

\section{RESUMO}

Considerados artífices da palavra Merleau-Ponty e Vinicius de Moraes (separados no tempo e no espaço) estão unidos pelo fazer filosófico e poético. O presente texto objetiva compreender as aproximações entre a filosofia de Merleau-Ponty a partir do sensível e a poesia cantada de Vinicius de Moraes a partir da paixão. Parte de uma abordagem fenomenológica pautada nos estudos de Merleau-Ponty (1999) tomando como técnica de pesquisa a descrição merleaupontyana.

PALAVRAS-CHAVE: Sensível; música; poesia; paixão.

\section{THE SENSITIVE IN MERLEAU-PONTY AND EXCITEMENT OF PASSIONS IN VINICIUS DE MORAES}

\section{RESUMO}

Considered craftsmen word Merleau-Ponty and Vinicius de Moraes (separated in time and space) are united by philosophical and poetic do. This paper aims to understand the similarities between Merleau-Ponty from sensitive and poetry sung by Vinicius de Moraes from passion. Part of a phenomenological approach guided the studies of Merleau-Ponty (1999) taking as a research technique to merleaupontyan description.

KEYWORDS: Sensitive; music; poetry; passion 


\section{O FILÓSOFO DO SER SENSÍVEL E O POETA DAS PAIXÕES}

Que pontos em comum existem entre Merleau-Ponty e Vinicius de Moraes? Ambos são considerados artífices da palavra, separados no tempo e no espaço, no entanto unidos pelo fazer filosófico e poético. O primeiro, filósofo nascido na França, o outro, brasileiro, diplomata, poeta do século $\mathrm{XX}$, criador de versos definitivos sobre a linguagem amorosa.

Distantes num curto espaço de tempo, Merleau-Ponty nasceu em 1908 e Vinicius de Moraes em 1913, e separados por um oceano, aproximam-se pelo gosto pela filosofia e pela arte. Merleau-Ponty foi criado por sua mãe após ter perdido o pai durante uma batalha na I Guerra Mundial; Vinicius de Moraes ao contrário, cresceu num ambiente de histórias frágeis, calcadas em fatos arrumados ao sabor das fantasias que o legitimou. Vinicius de Moraes veio de uma família de homens sensíveis e mulheres impressionáveis; Merleau-Ponty, apesar da perda do pai, parece ter tido uma infância feliz, como bem descreve em passagens da Fenomenologia da Percepção (1999, p. 463) "Se me reporto a esses anos, tais como os vivi e os trago em mim, sua felicidade recusa-se a deixar-se explicar pela atmosfera protegida do ambiente familiar, é o mundo que era mais belo, as coisas que eram mais atraentes, e nunca posso estar seguro de compreender o meu passado melhor do que ele se compreende a si mesmo quando o vivi, nem fazer calar seu protesto".

Em suas paixões femininas o filósofo Merleau-Ponty foi reservado, o poeta Vinicius de Moraes ao contrário deixava-se envolver por suas paixões, é tanto que casou nove vezes. Merleau-Ponty casou-se uma única vez com Suzanne com quem teve uma filha, Marianne; e antes do casamento teve um envolvimento frustrado com Elisabeth, a Zazá (BEAUVOIR, 2000). Vinicius de Moraes casou-se com Beatriz de Azevedo de Mello Moraes (Tati), Regina Pederneiras, Lila Esquerdo Boscoli, Lucinha Proença, Nelita de Abreu Rocha, Cristina Gurjão, Gesse Gessy, Marta Rodriguez e Gilda de Queiroz Mattoso. Com cada uma de suas mulheres o poeta da Bossa Nova viveu intensas paixões e buscava algo distinto: um desejo rimbaudiano de changer la vie, mas projetado em clave exclusivamente feminina (CASTELLO, 1994).

Merleau-Ponty foi um apaixonado pela filosofia apesar de questioná-la, Vinicius de Moraes um apaixonado pela poesia. O filósofo francês foi influenciado pela fenomenologia de Husserl, sobretudo pela possibilidade de se refletir sobre a vida cotidiana (CHAUÍ, 1980); o poeta brasileiro teve influências de Arthur Rimbaud que teria tido papel importante na passagem da poesia metafísica do poeta para uma poesia do cotidiano (CASTELLO, 1994).

Merleau-Ponty, filósofo da Fenomenologia da Percepção, sua obra fundamental, foi professor da Universidade de Lyon, da Sorbonne e do Collège de France, dividiu a direção da revista Les Temps Modernes com Sartre e escreveu vários ensaios dedicados ao ensino da filosofia, escreveu sobre a arte (em especial a pintura), a linguagem e a estética (um exame sobre a pintura e sobre o sensível como modo de conhecimento). Elegeu o corpo como tema privilegiado de sua filosofia (CHAUÍ, 1980); Vinícius de Moraes foi um grande escritor da emoção, da sedução e da exaltação da figura feminina em sua época. Soube liricamente escrever, cantar e fazer a arte do amor tipicamente sensual. O poeta que tudo viveu e tudo sentiu foi músico, boêmio, diplomata, escritor, poeta e amante das mulheres, conseguiu contribuir ricamente para a cultura brasileira e marcou gerações (CASTELLO, 1994, MOISÉS, 1980). 
O filósofo e o poeta foram apaixonados pelo que faziam. A paixão, afirma MerleauPonty, é o retirar o véu das coisas como mero objeto, como coisificação de si mesmo, porque o homem é corroído pelo desejo do ser e tem nele mesmo a necessidade de preencher o vazio desse desejo inacabado. (MERLEAUPONTY, 2000, p. 222). A paixão para Vinicius de Moraes dava-se pela transitoriedade e pelo risco. "Carlos Drummond de Andrade [...] certa vez disse que Vinicius era o único poeta brasileiro que ousou viver sob o signo da paixão" (CASTELLO, 1994, p. 11). Para o poeta poesia sem paixão poderia ser tudo, menos poesia.

O presente texto objetiva compreender as aproximações entre a filosofia de MerleauPonty a partir do sensível e a poesia cantada de Vinicius de Moraes a partir da paixão. Parte de uma abordagem fenomenológica pautada nos estudos de Merleau-Ponty (1999) tomando como técnica de pesquisa a descrição merleaupontyana. Cumpre frisar que a Fenomenologia trabalha com a descrição dos fenômenos. A descrição busca a "própria coisa", e, embora enraizada, encontra-se repleta de significados vividos dia a dia, "sem que isso seja conscientizado ou verbalizado". Há também a intuição que faz sobressair o que "já está aí", para melhor percebêlo. Não se trata de utilizar a imaginação apenas do ponto de vista poético, místico ou psicológico, como de costume, mas dar-lhe um novo significado, um novo interesse epistemológico, a partir das possibilidades sensíveis, relacionadas às experiências vividas pelos sujeitos humanos e comunicadas por meio de suas narrativas pessoais (depoimentos, biografias, expressões artísticas, literárias, fotografias, vídeos, entre outras). É preciso registrar que, embora os autores discutidos no texto não façam referência às imagens elas são necessárias para compreender esse sensível e essas paixões.

As imagens, na compreensão do pesquisador que é artista da cena e professor de dança ajudam a compreender essa ideia de sensível a partir da leitura de Merleau-Ponty e dos poemas de Vinicius de Morais. Elas não justificam o texto, mas complementam, apontam possibilidades de vislumbramento do sensível através da dança. Assim, as figuras de Kasuo Ono, dançarino de Butoh, de fragmentos do espetáculo Tatyana de Deborah Colker Cia de Dança, dos fragmentos do Espetáculo "Ariana" da Escola Bolshoi no Brasil com músicas de Vinicius de Morais nos dar a pensar esse corpo estesiológico, sensível.

\subsection{O SER SENSÍVEL EM MERLEAU-PONTY: ALGUMAS NOTAS PRELIMINARES}

Abbagnano (2000, p. 872) define sensível como sendo "aquilo que pode ser percebido pelos sentidos". O sensível ainda é para o citado autor "[...] objeto do conhecimento" e ainda "quem tem a capacidade de compartilhar as emoções alheias ou de simpatizar".

Merleau-Ponty em suas análises do sensível convida-nos a voltar ao objeto estético e conferir sua força de provocação, sensível que comunga do mesmo corpo do sentido, como um cavaleiro forma um conjunto com o cavalo ou a mão com a ferramenta.

O sensível em sua obra não é apenas para ser entendido, mas ser vivido. Esse sentido na compreensão merleaupontyana não é algo sólido, um objeto, uma cor; é antes de tudo uma ideia mais ampla, é a atitude do corpo que nos mobiliza, que nos paralisa para algo. Logo nas obras, a exemplo de Fenomenologia da Percepção (capítulo Sentir), O olho e o Espírito (os ensaios A linguagem indireta e as vozes do silêncio e A dúvida de Cézanne) e Signos (O filósofo e sua sombra), o sensível é uma postura corpórea. 
O sujeito da sensação não é nem um pensador que nota uma qualidade, nem um meio inerte que seria afetado ou modificado por ela; é uma potência que co-nasce em um certo meio de existência ou se sincroniza com ele (MERLEAUPONTY, 1999, p. 285).

Para a compreensão dessa noção de sensível, Merleau-Ponty apresenta uma crítica ao pensamento objetivo de ciência (Positivismo, Behaviorismo, Gestalt, Fisiologia Clássica, Psicologia Cognitivista, Empirismo, Critícismo e a própria Filosofia) posto que esse pensamento objetivo ignora o sujeito da percepção, ou seja, ignora o corpo.

O pensamento de Merleau-Ponty demonstra insatisfação para com a pesquisa de tipo positivista, que defende como válido para o âmbito humano o mesmo modelo de aferimento aplicado pelas ciências ditas exatas. Merleau-Ponty, no ensaio "O olho e o espírito", critica na ciência aquilo que ele chama de "pensamento de sobrevoo", ou seja, aquele pensamento que não se aprofunda sobre as coisas e transforma aquilo que vê, na superfície, em ideia ou conceito sobre o mundo e passa a operar apenas com esses conceitos.

É importante observar as críticas que o filósofo faz à ciência de maneira geral:

A ciência manipula as coisas e renuncia a habitá-las. Fabrica para si modelos internos delas e, operando sobre esses índices ou variáveis as transformações permitidas por sua definição, só de longe em longe se defronta com o mundo atual (MERLEAU-PONTY, 2004, p. 13).

Para o filósofo o sensível é o ato de sentir; é o campo estesiológico, o quiasma, o entre. Pode-se exemplificar esse corpo sensível com as obras de Cézanne, na dança-teatro Butoh ${ }^{1}$ e de Pina Bausch ou ainda na dança contemporânea de Deborah Colker ou mesmo ainda na pintura expressionista de Picasso.

A dança-teatro Butoh (figura 1) é um exemplo do corpo sensível que podemos fazer relação com o termo na obra merleaupontyana. Adentrar nos contornos dessa manifestação artística contemporânea é considerar o saber integrativo que é próprio do corpo, o seu saber não fragmentado, que imbrica a parte no todo, a razão na emoção, a natureza na cultura, o sensível. É considerar, também, que o corpo nessa dança revela uma beleza que rompe com a mecanização gestual, isso porque há uma experiência de indivisibilidade entre a percepção e o pensamento. Espaço do Ser que sente e do que vai ser sentido; é o que não foi, o que não chegou, logo a sensibilidade. É o espaço em que o corpo nos coloca em situação de Ser que sente e sempre há um espaço do que vai ser sentido. O sensível de que fala Merleau-Ponty é o ato da radicalidade, das emoções, do próprio conhecimento.

\footnotetext{
${ }^{1} \mathrm{O}$ butoh é um dos gêneros da dançateatro em evidência no cenário da estética contemporânea. Nasceu no ambiente da vanguarda japonesa, em fins da década de 1950, num contexto sociocultural marcado pela repressão e agressão ocidentais. Seus espetáculos abordam temas como o nascimento, a morte, o inconsciente, a sexualidade, o grotesco.
} 


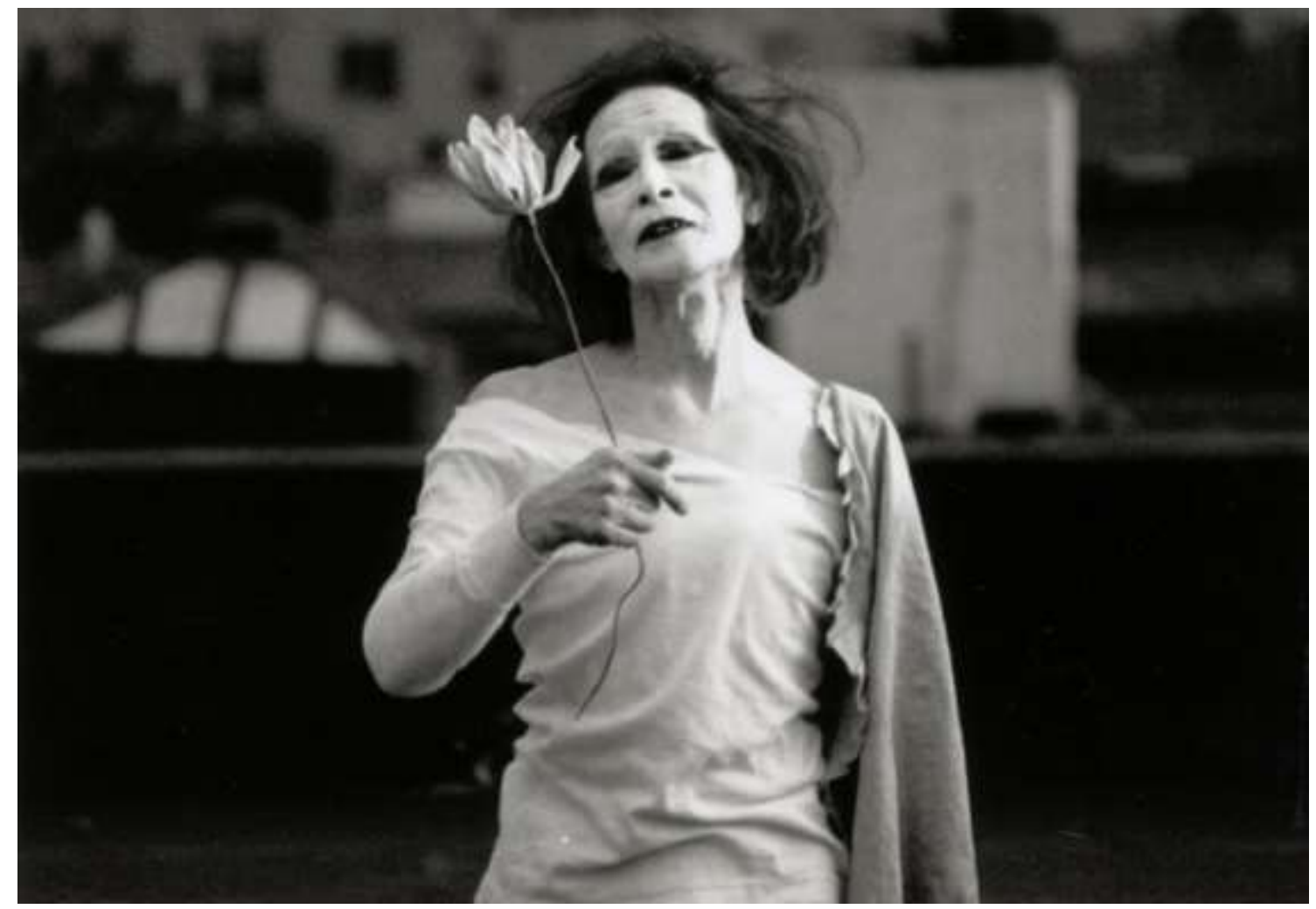

Figura: 1- representações de um corpo estesiólogico. Kasuo Ono, dançarino de Butoh.

Para Merleau-Ponty (1999) a espessura do sensível é sempre parcial. "Nossa experiência é a experiência de um mundo" (MERLEAU-PONTY, 1999, p. 299).

Em seus últimos textos o corpo e a linguagem sensível assumem aspectos de complexidade sendo este corpo movimento, expressão criadora e sensibilidade. Pelo "corpo próprio", há a experiência sensível do "ser-no-mundo", na ordem do que é vivido e não do que é pensado, pois o sentir é pré-objetivo. Isso se dá pela relação "eu, o outro e as coisas" em estado nascente, admitindo uma expressão vital primordial, que desencadeia numa relação ontológica do corpo enquanto abertura a um sentido sensível do mundo estabelecendo uma relação com aquilo que pertence à ordem do que é vivido e não meramente do que é pensado. A evidência que se tem do outro, parte da sensibilidade e não do pensamento, pois há uma universalidade do sentir, uma vez que se vive o mesmo mundo um corpo que entra em contato com outro.

O pensamento de Merleau-Ponty (1999) evidencia aspectos fundamentais para o entendimento do que é o corpo. Para o autor, o corpo é uma simultaneidade de sujeito e objeto existindo num espaço-tempo e servindo de referência central ao processo perceptivo. Essa simultaneidade destaca o aspecto fenomenológico do corpo, um corpo sensível e inteligível, datado e localizado espacialmente, que traduz a sensibilidade do ser e toda a memória do vivido. 


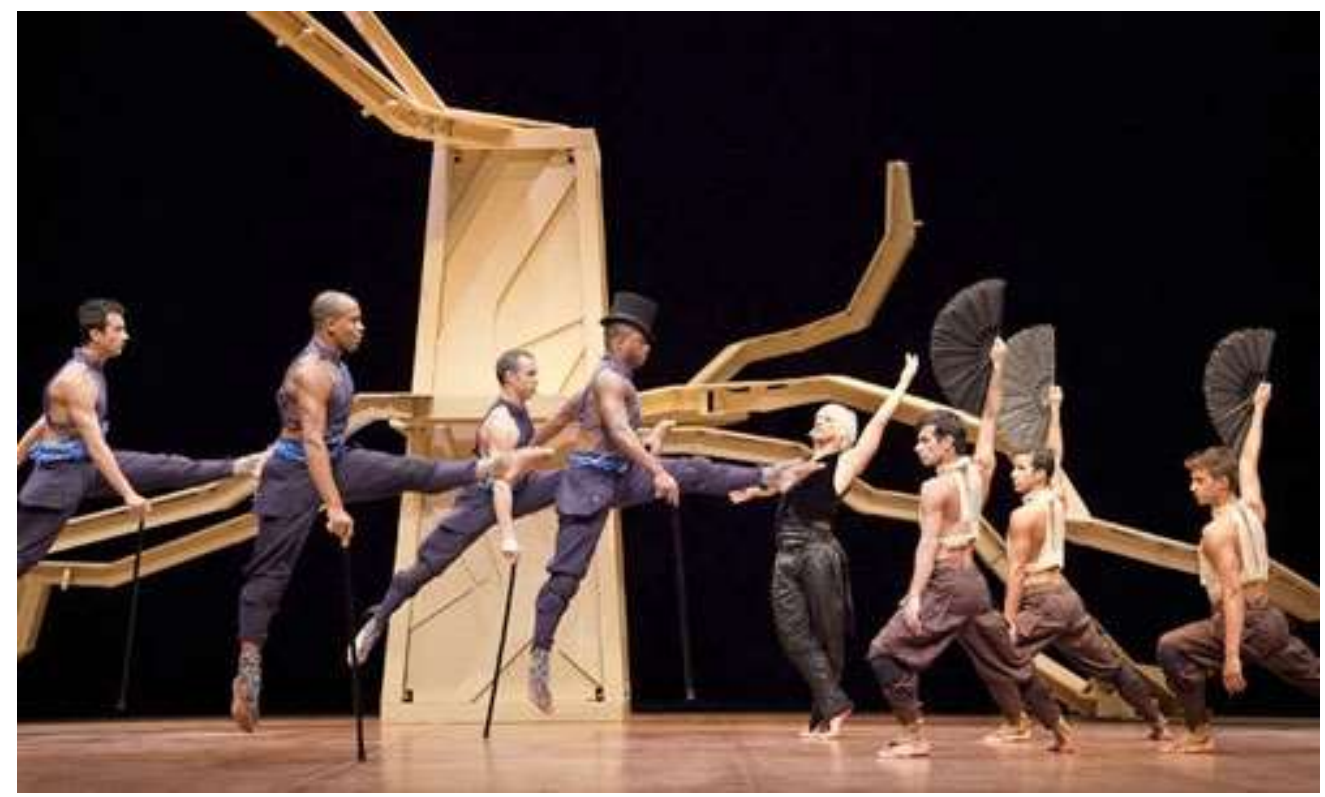

Figura: 2 - corpo sensível. Deborah Colker Cia de Dança. Fragmento do espetáculo Tatyana.

O corpo não é só uma soma de órgãos justapostos, e sim um sistema sinérgico nos quais todas as funções são retomadas. O corpo é a textura comum de todos os objetos e, em relação ao mundo percebido, o mundo geral da compreensão é o lugar e a própria atualidade do fenômeno da expressão; nele, as experiências sensoriais são impregnantes umas das outras (MERLEAU-PONTY, 1999). É a realidade do corpo que nos permite sentir e, portanto perceber o mundo, os objetos, as pessoas. É a realidade do corpo que nos permite imaginar, sonhar, desejar, pensar, narrar, conhecer, escolher.

É no corpo que o sensível é objeto de conhecimento que constitui a síntese da percepção e do movimento, que tem a capacidade de compartilhar as emoções alheias ou de simpatizar e que segundo Nóbrega (2000, p. 104) "relaciona o corpo a unidade do humano, uma unidade que se revela na diversidade, aproximando a linguagem do corpo da expressão artística, do viés sensível. A linguagem sensível privilegia a beleza, a poesia e a diversidade da linguagem corporal".

Entendemos esse sensível como uma atitude do corpo em cada ato. Para Merleau-Ponty (1999) o sensível é o ato senciente; é o corpo estesiológico, a relação entre eu e o mundo pelo meu corpo, não relações entre partes do mundo. Espaço do Ser que sente e do que vai ser sentido; é o que não foi e o que não chegou, logo, a sensibilidade. É o espaço em que o corpo nos coloca em situação de Ser que sente e sempre há um espaço do que vai ser sentido. 0 sensível de que fala Merleau-Ponty $(1999,2004)$ é o ato da radicalidade, das emoções, do próprio conhecimento.

Esse sensível, para Merleau-Ponty (1991, 1999, 2004), em especial no ensaio “O filósofo e sua sombra", é constituinte no nível do ser e do conhecimento, da síntese da percepção e do movimento.

A carne do sensível, esse grão concentrado que detém a exploração, esse ótimo que a termina refletem a minha própria encarnação e são a 
contrapartida dela. Há aí um gênero do ser, um universo com seu "sujeito" e com seu "objeto" sem iguais, a articulação de um no outro e a definição de uma vez por todas de um "irrelativo" de todas as "relatividades" da experiência do sensível, que é fundamento de direito para todas as construções do conhecimento. Todo o conhecimento, todo o pensamento objetivo vivem desse fato inaugural que senti, que tive com essa cor ou qualquer que seja o sensível em causa, uma existência singular que tolhia repentinamente o meu olhar, e, contudo prometia-lhe uma série indefinida de experiências, concreção de possíveis desde já reais nos lados ocultos da coisa, lapso de duração dado numa só vez (MERLEAU-PONTY, 1991, p. 184).

Tais considerações sobre o sensível, em Merleau-Ponty (1991, 1999, 2004), tornam as experiências do corpo únicas, singulares, abertas a diferentes interpretações e vivências, a partir de suas constantes relações com o mundo, criando, como diria Nóbrega (1999), possibilidades de novas formas de elaboração do conhecimento. Há uma imbricação desse cenário do sensível com o vivido e com o mundo, ou seja, com o mundo vivido enquanto fonte primordial de conhecimento, pois, ao estarmos abertos a esse mundo, comunicamo-nos com ele.

\subsection{A EXCITAÇÃO DAS PAIXÕES NO POETA DA BOSSA NOVA}

Em Vinicius de Moraes a paixão é encontrada na concepção da mulher espiritualizada, de acordo com a formação religiosa que havia recebido na infância e na juventude e em conformidade com os conceitos da poesia simbolista, da qual bebeu avidamente, para num momento seguinte de seu fazer poético, ao estabelecer uma comunhão com o cotidiano, transformar-se num poeta extremamente sensual, trazendo a mulher ao mundo do real e do corpóreo (CASTELLO, 1994; BISSIATTI, 2006).

Vinícius de Moraes possui múltiplas visões da mulher e, enquanto escritor dedicou grande parte de sua obra a elas. Por suas tendências patriarcais e também lírico-amorosas, criou um emaranhado de poemas que valorizam e enaltecem a figura feminina, vítima de tanta opressão e injustiça. O despertar da era moderna fez o despertar dessa mulher, levando-a à ação, fazendo-a ser vista numa perspectiva antagônica como virtude e pecado, santa e demônio, bem e mal na obra do poeta (BISSIATTI, 2006).

Amava louras e morenas, era tocador de violão e bom dançarino, não lhe faltavam garotas nem amigos. Confessou à mãe que desejaria ser amado por todas as mulheres e ser amigo de todos os homens. Esse amor plural de Vinícius estendia-se aos amigos, familiares e à alegria. Privou da alegria de centenas de noites varadas com amantes e amigos, fazendo amor, poesia e canções.

Vinícius era realmente uma pessoa influente na sociedade local e seus relacionamentos eram incontáveis, fossem eles de amigos ou de amantes. Para ele, se fossem somente as mulheres, seria mais fácil interligá-las, mas não: eram súditos, amigos, irmãos, parceiros, melhores amigos em cada estado ou cidade, conhecidos episódicos de uísque e de conversa. Quem teve o privilégio de desfrutar da intimidade do velho Vina, jamais se esquece de sua 
doçura quase infantil, da excitação arrebatadora que sentia pela vida e também de seus conflitos. O maior deles: o álcool. Depois das mulheres, o uísque era a maior paixão do poeta (GENTE DO SÉCULO, 1999; BISSIATTI, 2006).

Suas musas foram o papel em branco e macio em que pintou o retrato de Eros com as mais distintas vestes. Imensa necessidade de viver sob o estado revolucionário da paixão. Valia tudo por uma grande paixão. Amava como um príncipe doce e perverso que rouba donzelas (BISSIATTI, 2006).

Vinicius de Moraes foi o poeta da imperfeição; seu tema por excelência foi a antiutopia, ou seja, o limite do homem diante de seus desejos. A poesia do poeta começa como um voto de resignação ao desconhecido, ao obscuro, ao vazio isto é, a fraqueza humana. Atravessa essa poesia de sua formação religiosa para uma poesia que se lançava como uma ponte sobre o abismo. É por meio dessa descoberta da poesia ciente do vazio essencial do humano que o poeta chega à celebração da vida. Celebração poetizada em seus nove amores: a paixão pela beleza aguda e pelo desconcerto, a paixão em estilo clássico, a paixão pelo álcool e por uma forma de obsessão em sua poesia-música, a paixão de um amor moreno violento e desesperançado, a paixão como uma forma de exílio, a paixão como marca de serenidade e a paixão não como um fim, mas apenas um início (CASTELLO, 1994).

Na fase inicial, o poeta privilegiou o espiritual e o transcendental, compondo poesias de cunho místico, numa reafirmação do homem com Deus, resultante de sua fase cristã. Essa fase desencadeou uma série de poemas metafísicos em que o conflito entre carne e espírito esteve sempre presente. No poema "Invocação à mulher única", podemos perceber essas características femininas envoltas em mistério e misticismo:

\section{$[\ldots]$}

O Novo Testamento afirmações do bem: dúvida

(Dúvida mais fácil que a fé, mais transigente que a esperança,

[mais oportuna que a caridade

Dúvida, madrasta do gênio) - tudo, tudo se esboroa

[ante a visão do teu ventre púbere, alma de

Pai,

[coração do Filho, carne do Santo Espírito, amém!

[...] (MORAES, 1986. p.141)

Em fase posterior, a de linguagem mais simples e voltada para o real, Vinícius de Moraes compõe versos líricos decorrentes do cotidiano, da experiência diária e do encontro íntimo entre o transcendental e o humano. Como exemplo dessa fase, podemos destacar os sonetos: "Soneto do maior amor", "Soneto do amor total", "Soneto de separação" e ainda o seu mais conhecido e de total renome "Soneto de fidelidade". 
De tudo, ao meu amor serei atento

Antes, e com tal zelo, e sempre, e tanto

Que mesmo em face de maior encanto

Dele se encante mais meu pensamento.

Quero vivê-lo em cada vão momento

E em seu louvor hei de espalhar meu canto

E rir meu riso e derramar meu pranto

Ao seu pesar ou seu contentamento.

E assim, quando mais tarde me procure

Quem sabe a morte, angústia de quem vive

Quem sabe a solidão, fim de quem ama

Eu possa me dizer do amor (que tive):

Que não seja imortal, posto que é chama

Mas que seja infinito enquanto dure (MORAES, 1992, p.93).

Esses versos, conforme nos acrescenta Castello (1994) guardam uma das mais belas definições do amor já produzidas pela língua portuguesa e ainda descrevem a essência da visão que o poeta terá do amor ao longo de sua vida, que traz a sensação de eternidade, mas que necessariamente um dia acabará.

Castello (1994) nos informa que durante o momento de inspiração poética de Vinícius, verdades muito íntimas do poeta eram reveladas e apreendidas num instante de reflexão e emoção, espalhando sua poesia pela realidade e fazendo dela a sua vida. 


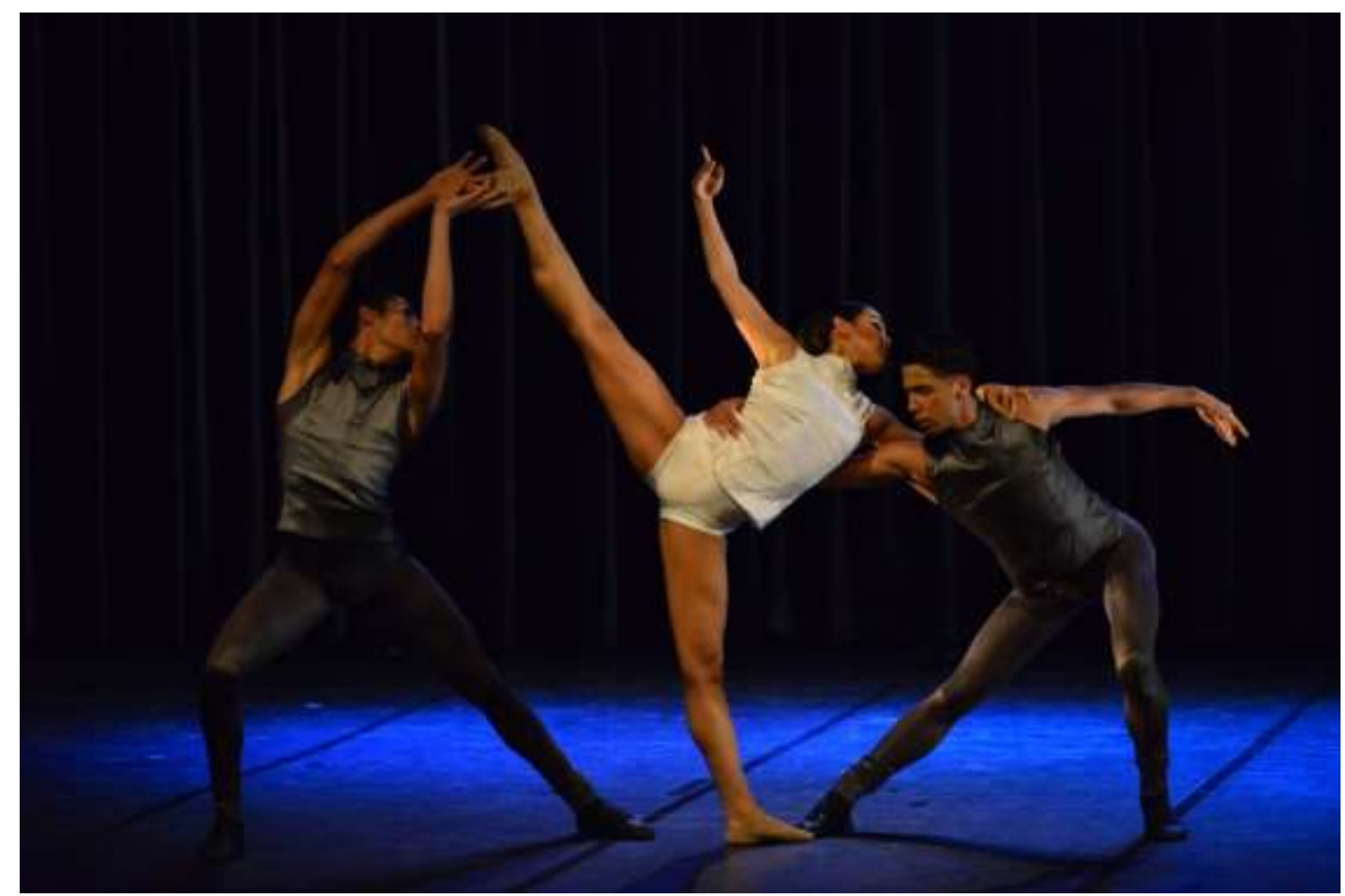

Figura: 3 - Fragmento do Espetáculo “Ariana”, Escola Bolshoi no Brasil.

Quando escreveu o poema "Ariana, a Mulher", Vinícius de Moraes provavelmente não imaginava que um dia a essência daquela alma feminina seria captada por uma coreógrafa e transformada em uma peça de dança, transportando para o palco a feminilidade que o poeta colocou no papel.

Vinícius de Moraes conseguiu mostrar, através de sua escrita e visão múltiplas, os diversos mistérios existentes na figura feminina, bem como dissecá-la a ponto de descobrir os seus desejos e anseios mais reprimidos e torná-los visíveis para que seus leitores pudessem apreciar e ao mesmo tempo fazer parte de um mundo que até então era só dele. Vinícius, ao escrever sobre a mulher, tentou recriá-la sobre diversos ângulos, desde a mulher submissa, objeto de desejo, até aquela endeusada, de forma quase transcendental, das ricas até as mais pobres, das cultas às analfabetas, das livres às escravas (CASTELLO, 1994; GENTE DO SÉCULO, 1999; BIASSATTI, 2006).

Com a entrada da mulher em cena, agora não mais como um ser ideal e inatingível, mas como um ser de carne, osso e coração, começa a nascer o grande poeta brasileiro do amor. Para ser mais exato: poeta da paixão (CASTELLO, 1994).

Agora a mulher não está mais encoberta pela cortina do espírito; a carne se sobrepõe a alma. Surgem em sua poesia à mulher fatal, a mulher deusa escrita pelo poeta como deusa, rainha e poderosa e a mulher-objeto que para o poeta com toda sua ardente sexualidade tropical, a mulher não precisaria nem falar para se expressar, basta um olhar ou um gesto que a mensagem se faz; mesmo não falando, ela significa e manipula a linguagem: a linguagem do 
olhar, dos gestos, do corpo e da sedução. O poeta também valoriza o racionalismo quando diz que beleza é fundamental.

As muito feias que me perdoem

Mas beleza é fundamental. É preciso

Que haja qualquer coisa de flor em tudo isso

Qualquer coisa de dança, qualquer coisa de haute couture

Em tudo isso (ou entao

Que a mulher se socialize elegantemente em azul, como na República

Popular Chinesa).

Não há meio-termo possível. É preciso

Que tudo isso seja belo. É preciso que súbito

Tenha-se a impressão de ver uma garça apenas pousada e que um rosto

Adquira de vez em quando essa cor só encontrável no terceiro minuto da aurora.

É preciso que tudo isso seja sem ser, mas que se reflita e desabroche No olhar dos homens. É preciso, é absolutamente preciso

Que seja tudo belo e inesperado. É preciso que umas pálpebras cerradas Lembrem um verso de Élaurd e que se acaricie nuns braços

Alguma coisa além da carne: que se os toque

Como no âmbar de uma tarde. Ah, deixai-me dizer-vos

Que é preciso que a mulher que ali está como a corola ante o pássaro

Seja bela ou tenha pelo menos um rosto que lembre um templo e

Seja leve como um resto de nuvem: mas que seja uma nuvem

Com olhos e nádegas. Nádegas é importantíssimo. Olhos, entao

Nem se fala, que olhem com certa maldade inocente. Uma boca

Fresca (nunca úmida!) é também de extrema pertinência. [...]

(MORAES, 1992, p.227, 228)

Vinícius de Moraes é o poeta do amor impossível, da loucura passageira e da efervescência do juízo. Foi um homem que preferiu invadir o coração das mulheres apostando na sua força sedutora. Para ele, a paixão sem limites triunfaria sobre a razão e a sua vida seria para sempre assim. Conseguiu retratar em sua produção poética um verdadeiro emaranhado de visões acerca desse seu instrumento de prazer e fonte infindável de inspiração. Viveu para amar e ser amado e amou incondicionalmente. José Castello finalmente nos acrescenta "Vinícius: um 
homem para quem o sofrimento era apenas um intervalo entre duas felicidades" (CASTELLO, 2004. p.430).

Compôs letras que o consagram eternamente na música popular brasileira. Em suas canções populares, podemos perceber algumas dessas composições que fizeram de Vinícius o eterno compositor do amor e da saudade e que enriqueceram os arquivos melódicos da música popular. Garota de Ipanema e Chega de Saudades, Ariana, a mulher são grandes exemplos (BIASSATTI, 2006).

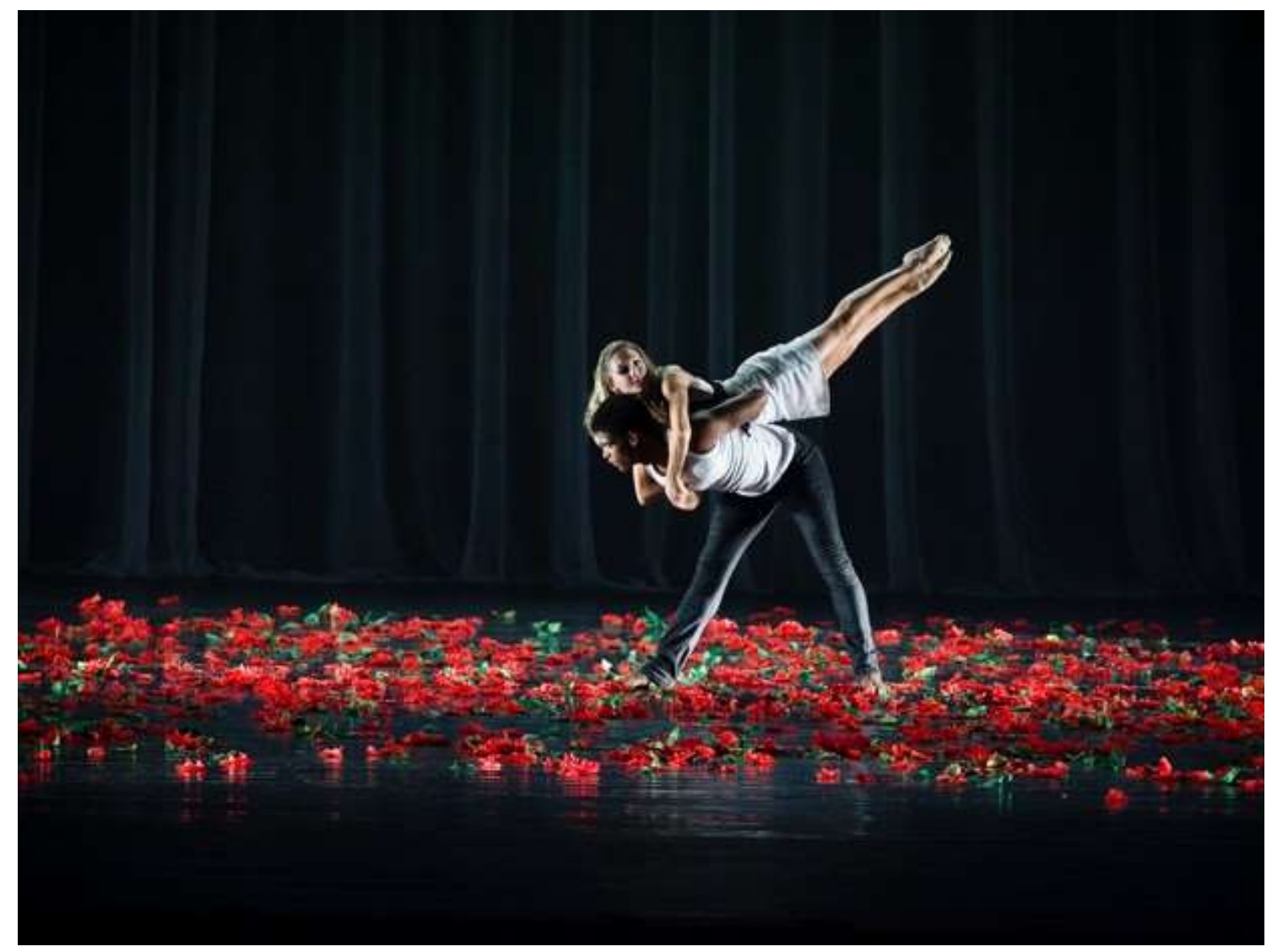

Figura: 4 - Fragmento do Espetáculo “Ariana”, Escola Bolshoi no Brasil.

Como um dos grandes representantes do lirismo amoroso dos tempos atuais, Vinícius conseguiu, como poucos, exprimir com realismo característico a relação de amor entre o homem e a mulher. "O amor não anula a legitimidade de seus sentimentos pelas mulheres com quem se relacionou. Elas foram agentes detonadores do sentimento amoroso. Cada uma delas foi uma face de percepção amorosa" (BIASSATTI, 2006, p. 41).

\section{RELAÇÕES ENTRE}

O filósofo e o poeta são artífices da palavra. Merleau-Ponty um apaixonado pela filosofia e pela arte, em especial a pintura, Vinicius de Moraes um apaixonado pela poesia e pela música. 
Se ambos pudessem ter se conhecido talvez o poeta diria para o filósofo: "se todos fossem iguais a você/ que maravilha viver!"

Se ambos tivessem trocado cartas assim como Merleau-Ponty fez com Sartre e Vinicius de Morais com seu amigo Octavio de Faria, talvez o poeta escrevesse para o filósofo falando de seus amores e a ele diria: "De tudo, ao meu amor serei atento/ antes, e com tal zelo, e sempre, e tanto/ que mesmo em face do maior encanto/ dele se encante mais meu pensamento". 0 filósofo responderia: "O mundo não é aquilo que eu penso, mas aquilo que vivo, sou aberto ao mundo, me comunico indubitavelmente com ele, mas não o possuo, ele é inesgotável".

Vinicius de Morais em suas cartas regadas a uísque talvez diria ao filósofo dos seus amores, de suas paixões, de sua poesia, de sua exaltação ao amor e a mulher e de repente escreveria para Merleau-Ponty sobre separação: "De repente do riso fez-se o pranto/silencioso e branco como a bruma/e das bocas unidas fez-se a espuma/ e das mãos espalmadas fez-se o pranto [...] Fez-se do amigo próximo o distante/fez-se da vida uma aventura errante/ de repente, não mais que de repente". O filósofo entenderia o poeta e lhe retrucaria escrevendo sobre o mundo vivido como o húmus de todos os nossos atos, o solo de todas as nossas atitudes, a camada primordial, anterior a toda multiplicidade cultural. Esse mundo é, por definição, único, é por ele que o sujeito se conhece, comunica-se com ele, sem possuí-lo, posto que ele seja inesgotável.

Vinicius de Moraes insistiria em seus amores e recitaria em uma dessas cartas ao filósofo, "Epitáfio" (MORAES, 1992, p.221): “Aqui jaz o sol/Que criou a aurora/E deu luz ao dia/ E apascentou a tarde/ [...] Aqui jaz o sol/ O andrógino meigo/ E violento, que/ Possui a forma/ De todas as mulheres/ E morreu no mar." O filósofo retrucaria ao poeta escrevendo sobre o sensível para compreender tais amores:

O fato é que o sensível, que se anuncia para mim em minha vida estritamente privada, interpela toda outra corporeidade através da minha. Ele é o ser que me atinge no que tenho de mais secreto, mas também, que atinge em estado bruto ou selvagem, num absoluto de presença detentor do segredo do mundo, dos outros e do verdadeiro. Há nele "objetos" que não estão originalmente presentes somente para um sujeito, podem idealmente ser dados em presença originaria para todos os outros sujeitos a partir do momento em que estão constituídos (MERLEAU-PONTY, 1991, p. 441, 442).

Provavelmente o poeta e o filósofo ficassem trocando cartas até um encontro em um café parisiense ou em uma praia no Rio de Janeiro e dessas cartas e encontro(s) falassem do sensível como algo que não se deva ser eliminado por conter erros, por ser uma ilusão, mas por dar-se na carne do meu corpo através do olhar e da carne do mundo que é um conjunto de experiências humanas e só pode ser configurado e protagonizado por um corpo, e qualquer forma de distanciamento entre o homem e o mundo sensível merece ser questionada. 0 corpo próprio ou vivido constitui a maneira pela qual nos instalamos no mundo, tanto ganhando quanto doando significação. 
O sensível, dessa forma, é a experiência do pensamento, é uma espécie do Ser, é um apelo à palavra, quer seja pelo corpo, quer seja pela memória. O sensível se encarna no corpo e é, também, uma prolongação de sua carne. As coisas, então, não existem mais em si, sendo aqui e agora, em seu lugar e em seu tempo; elas "[...] só existem no término destes raios de espacialidade e temporalidade, emitidos no segredo da minha carne, e sua solidez não é a de um objeto puro que o espírito sobrevoa, mas é experimentada por mim do interior enquanto estou entre elas, e elas se comunicam por meu intermédio como coisa que sente" (MERLEAUPONTY, 2007, p. 113).

O sensível é uma atitude corporal. Um sensível que é constituído de significações nas relações do ser com o mundo, sensível que se constitui sobremaneira como ponto de partida para a apreensão de parcelas do mundo pelo corpo e que o transforma em um conteúdo dotado de significações e sentidos.

Mas como articular uma teoria do sensível merleaupontyana a música de Morais? Penso que esta seja uma ideia cara e que necessite de um maior aprofundamento no termo sensível empreitado pelo filósofo. Recorro então a estudiosos ou comentadores da obra de MerleauPonty para tal empreitada já que como artista com um olhar sensível para os escritos do filósofo francês, para a música popular brasileira do poeta Vinícius de Morais e o entrelaçamento desse sensível nas figuras citadas compreender a articulação desse corpo sensível no filósofo, no poeta e nas imagens.

Nóbrega (2015) argumenta que o corpo sensível exemplar em Merleau-Ponty remete-se à profundidade da carne como carne do corpo e do mundo. Nas palavras do filósofo supracitado sua compreensão dessa noção de corpo como sensível exemplar:

O corpo interposto não é propriamente coisa, matéria intersticial, tecido conjuntivo, mas sensível para si, o que quer dizer não este absurdo: cor que se vê, superfície que se apalpa, mas este paradoxo: conjunto de cores e superfícies habitados por um tato, uma visão, portanto, sensível exemplar, que capacita a quem o habita e o sente sentir tudo o que se assemelha, de sorte que, preso no tecido das coisas, o atrai inteiramente, o incorpora e, pelo mesmo movimento, comunica às coisas sobre as quais se fecha, essa identidade sem superposição, essa diferença sem contradição, essa distância do interior e do exterior, que constitui seu segredo natal [ o mundo está no amago da carne...] (MERLEAUPONTY, 1964, p. 178).

Para pensar essa realidade do corpo sensível, Nóbrega (2015) pontifica que MerleauPonty evita as tentativas clássicas, os impasses tradicionais relacionados ao dualismo filosófico ou positivismo lógico e científico reconhecendo a dupla pertença do corpo, qual seja, a ordem do 'objeto' e à ordem do 'sujeito', assim como as relações inesperadas entre essas duas ordens. "[...] Assim irá propor uma terceira via que se configura nas relações corpo e mundo e que se encontra delineada na noção de carne e sua relação com a visibilidade e a sensibilidade" (NÒBREGA, 2015, p. 82).

Sendo assim a noção de carne envolve o quiasma corpo e mundo, a relação sinérgica com outros corpos e arrisco-me a dizer a nossa relação com a música, com a dança, com os afetos, com a Arte. 
Nesse sentido a carne é o que é vagabunda, o ser da promiscuidade, profundidade e ligação com os outros, proliferante, tecendo por todo lado sua rede cerrada de ecos e analogias; ela é como dirá Merleau-Ponty um "simbolismo primordial" e não um corpo simplesmente animal. Ela é nossa luz natural, ou nosso pensamento bárbaro, mas também é racional quanto natural, pensante tanto quanto bárbara, ela é o lugar do habitar-se.

Compreendo que na música do poeta Vinicius de Morais tal sensível se dá no corpo, na carne quando escutamos sua melodia musical ou seus poemas que tratam desse ser sensível exemplar que é o humano.

\section{SEM PONTO FINAL}

Pensar a poesia de Vinicius de Morais e suas inter-relações com o sensível em MerleauPonty foi um desafio para essa escrita. Como já dito o poeta e o filósofo são artífices da palavra e cada um a sua maneira trataram do sensível quer na música, quer em seus escritos que tratam de uma estesiologia da carne. No poeta as canções amorosas apesar de apresentarem um caráter intimista, conduzem à leveza e à desconfiança das emoções desmesuradas e da lamentação pela perda irreparável. A relação com a palavra percorre o erudito e o popular, mesmo que inicialmente ligado a uma aristocracia poética, com a utilização mística dos signos, do vocabulário raro e nobre, aos poucos, o poeta se aproximou do cotidiano e da oralidade. Essa sua ampla compreensão sobre a língua foi determinante ao seu modo de escrever poesia e canções de música popular. Ao filósofo credita-se esse olhar sensível em particular para a pintura, o cinema e a literatura como uma filosofia do ser sensível uma opção paradoxal segundo Imbert apud Nóbrega (2015) em não buscar um corpo a quem remeter operações carimbadas por alguns séculos de filosofia clássica, mas demandar as figuras da arte moderna, em incessante reinvenção e pela inventividade mesma de retomada de questões engajadas no pensamento simbólico. Merleau-Ponty, por seu turno, parece ter entrevisto o quanto, na experiência da linguagem, as tarefas do escritor e do filósofo se solicitam mutuamente.

Em Sens et Non-Sens, prefacia Merleau-Ponty (1996, p. 7-8; 8):

Na presença de um romance, de um poema, de uma pintura, de um filme, válidos, sabemos que houve contato com alguma coisa, que alguma coisa tornou-se uma aquisição para os homens e a obra começa a emitir uma mensagem ininterrupta [...]. O mundo da cultura é descontínuo como o outro; também conhece surdas mutações [...]. Na obra de arte como na obra teórica, assim como na coisa sensível, o sentido é inseparável do signo. A expressão, portanto, nunca está acabada.

Ao tecer esse comentário, Merleau-Ponty chama a atenção para um traço geral de toda obra de arte: da literatura à pintura, passando pelo cinema, há algo de ininterrupto, descontínuo, inacabado, sensível. Tudo se passa como se cada uma dessas experiências estéticas portasse uma irresistível arma de sedução: seu intrépido esforço de exprimir, por diferentes recursos, o mundo, as coisas, os homens. Eis porque "[...] as palavras devem ser compreendidas conforme suas implicações laterais, não menos que em sua significação manifesta e frontal" (MERLEAU-PONTY, 1996, p. 160). É que a interexistência sensível da escrita arrasta também uma interexistência do sentido. 
Merleau-Ponty um poeta, portanto? Vinicius de Morais um fenomenólogo? É preciso medir melhor o real peso de tais comentários. O que, em rigor, a crítica não tarda em assinalar é que inexiste na concepção-de-mundo de Morais, qualquer influência externa ou direta de alguma teoria filosófica em particular e que inexiste na fenomenologia do filósofo traços de poesia.

O que cabe observar é que o impulso literário em Merleau-Ponty talvez se explique muito mais pela necessidade vital de se compreender uma filosofia do sensível; e se o poeta Vinicius de Morais jamais deixa de se impregnar com o tema da paixão é porque o eixo principal de seu trabalho já é animado por aquele princípio radicalmente malebranchiano que MerleauPonty teria antevisto em toda obra literária, ou seja, o seu o seu páthos fundamental, o "inacabamento".

\section{REFERÊNCIAS}

1. ABBAgnANO, Nicola. Dicionário de filosofia. Tradução de Ivone Castilho Benedetti. 4 ed. São Paulo: Martins Fontes, 2000.

2. BEAUVOIR, S. Memórias de uma moça bem-comportada. Rio de Janeiro: Nova Fronteira, 2000.

3. BISSIATTI, Almir Rodrigo. Vinicius de Moraes e a lírica da sedução. Dissertação (Mestrado em Letras). Centro de Ensino Superior de Juiz de Fora. Juiz de Fora, 2006.

4. CASTELLO, José. Vinicius de Moraes o poeta das paixões: uma biografia. São Paulo: Companhia das Letras, 1994.

5. CHAUÍ, Marilena de Souza. Merleau-Ponty: textos escolhidos. São Paulo: Abril Cultural, 1980. (Coleção: Os Pensadores).

6. GENTE DO SÉCULO: Vinicius de Moraes: o múltiplo das paixões. São Paulo: Editora Três Ltda, 1999.

7. MERLEAU-PONTY, Maurice. Le visible et l'invisible. Paris: Gallimard, 1964.

8.

Signos. Tradução de Ermantina Galvão Gomes Pereira. São Paulo: Martins Fontes, 1991.

9. . Sens et non-sens. Paris: Gallimard, 1996.

10. Fenomenologia da percepção. Tradução de Carlos Alberto Ribeiro de Moura. 2 ed. São Paulo: Martins Fontes, 1999.

11. MERLEAU-PONTY, Maurice. A natureza. Tradução de Álvaro Cabral. São Paulo: Martins Fontes, 2000.

12.

O olho e o espírito. Tradução de Paulo Neves e Maria Ermantina Galvão Gomes Pereira. São Paulo: Cosac \& Naify, 2004.

13. MOISÉS, Carlos Felipe. Vinicius de Moraes. São Paulo: Abril Educação, 1980. (Literatura Comentada).

14. MORAES, Vinicius. Antologia poética. São Paulo: Companhia das Letras, 1992. 15.

Poesia completa e prosa. Organizado por Afrânio Coutinho com assistência do autor. Rio de Janeiro: Nova Aguilar, 1986.

16. NÓBREGA, Terezinha Petrucia da. Para uma teoria da corporeidade: um diálogo com Merleau-Ponty e o conhecimento complexo. 1999. 220f. Tese (Doutorado em Educação). Universidade Metodista de Piracicaba. Piracicaba, 1999. 
17.

. Corporeidade e educação física: do corpo-objeto ao corposujeito. Natal: EDUFRN, 2000. 18. Sentir a dança ou quando o corpo se põe a dançar... Natal: IFRN, 2015. 